\title{
Production and Predator-Induced Release of Volatile Chemicals by the Plant Bug Lygus hesperus
}

\author{
John A. Byers
}

Received: 24 October 2005 / Revised: 21 April 2006/

Accepted: 7 May 2006 / Published online: 26 September 2006

C Springer Science + Business Media, Inc. 2006

\begin{abstract}
Both sexes of adult western tarnished plant bug, Lygus hesperus Knight (Heteroptera: Miridae), released three volatile chemicals in relatively large amounts when attacked by ants (Pogonomyrmex rugosus and Solenopsis xyloni) or when grabbed by forceps, as determined by solid-phase microextraction (SPME) and gas chromatographymass spectrometry (GC-MS). The relative amounts of the volatile compounds, hexyl butyrate, (E)-4-oxo-2-hexenal, and (E)-2-hexenyl butyrate, absorbed by SPME as a percentage of the largest were $100 \%, 44 \%$, and $4 \%$, respectively, from females, and $83 \%$, $37 \%$, and $3 \%$ from males. Both ant species were repelled by the defensive discharges (confirmed by SPME) when the ants attacked L. hesperus adults. Sexually mature $L$. hesperus were individually extracted in pentane to quantify the mean amounts of hexyl butyrate $(14.9 \mu \mathrm{g} /$ female; $10.3 \mu \mathrm{g} / \mathrm{male}),(E)$-4-oxo-2-hexenal $(2.7 \mu \mathrm{g} /$ female; $3.1 \mu \mathrm{g} /$ male), and $(E)$-2-hexenyl butyrate $(1.2 \mu \mathrm{g} /$ female; $0.6 \mu \mathrm{g} / \mathrm{male})$. (E)-4-Oxo-2-hexenal was unstable in solvent when in contact with a macerated adult, but relatively stable when the solution was decanted within minutes. The production of the three major volatile components began soon after the emergence of the adult and amounts increased for about 5-10 d with little or no increase thereafter. Minor additional constituents were crosscorrelated in many cases with the three major ones. A cost of defensive secretion is suggested for females but not for males, because heavier females produced more volatile compounds than lighter females. The initial discharge percentage, defined as the proportion of volatile compounds initially present that is discharged to defend against predation was
\end{abstract}

J. A. Byers $(\square)$

U.S. Arid-Land Agricultural Research Center, USDA-ARS, 21881 North Cardon Lane,

Maricopa, AR 85239, USA

e-mail: jbyers@wcrl.ars.usda.gov 
estimated at about $50 \%$ in males and $70 \%$ in females. Newly eclosed adults did not produce volatile chemicals until $2 \mathrm{~d}$ after molting.

Keywords Lygus hesperus $\cdot$ Heteroptera $\cdot$ Miridae $\cdot(E)$-4-oxo-2-hexenal $\cdot$ Hexyl butyrate $\cdot$ (E)-2-hexenyl butyrate $\cdot$ Pogonomyrmex rugosus $\cdot$ Solenopsis xyloni $\cdot$ Formicidae $\cdot$ Hymenoptera $\cdot$ Initial discharge percentage $\cdot$ Defensive secretion

\section{Introduction}

Plant bugs of the genus Lygus feed on meristematic tissues of plants, causing shedding of buds, blooms, seeds, and fruit (Debolt and Patana, 1985). There are at least nine species of Lygus bugs of economic importance in the northern hemisphere (Kelton, 1975), of which Lygus hesperus Knight is the most abundant in western North America (Clancy and Pierce, 1966; Kelton, 1975). The species is polyphagous, damaging cotton, alfalfa, and strawberries, and it is found on over 100 species of plants in 24 families (Scott, 1977; Blackmer et al., 2004). Several species in the genus, including L. hesperus, use a sex pheromone released by the female (Scales, 1968; Strong et al., 1970; Graham, 1987, 1988; McLaughlin, 1996). Several research groups have tried to identify the sex pheromone components of L. hesperus and Lygus lineolaris (prevalent in eastern United States) so far without success (Aldrich et al., 1988; Ho and Millar, 2002; Wardle et al., 2003).

Aldrich et al. (1988) extracted metathoracic scent glands and trapped airborne volatiles from $L$. hesperus and the sibling species L. lineolaris and found similar ratios of hexyl and $(E)$-2-hexenyl butyrate in males and females. (E)-4-Oxo-2-hexenal was also detected in glands of male $L$. hesperus and in both sexes of $L$. lineolaris. More recently, Ho and Millar (2002) found significant quantities of hexyl butyrate, $(E)$-2-hexenyl butyrate, $(E)$-2-hexenal, and 1-hexanol in solvent extracts of $L$. hesperus glands. These compounds, as well as lower amounts of additional components, were also found in aerations of the macerated adults. Although the sexes differed somewhat in the ratios of some components, each sex had all of the components. Field testing of all binary combinations of 16 components detected in aerations failed to attract either sex. Electroantennographic responses of each sex to 15 of the compounds indicated that both sexes can detect a wide range of compounds, including those from the macerated adults. Ho and Millar (2002) did not ascribe any biological function to the volatiles other than to suggest that one or more could be components of a sex pheromone blend.

Wardle et al. (2003) investigated volatile emissions from the sibling species L. lineolaris with the same goal of identifying a sex pheromone. They found that both sexes had large amounts of hexyl butyrate, $(E)$-2-hexenyl butyrate, and $(E)$-2-hexenal, with considerably more $(E)$-4-oxo-2-hexenal than in L. hesperus (compared with $\leq 1 \%$ by Ho and Millar, 2002) as collected by Porapak Q traps. The adults were crowded together in a mass at the bottom of a glass tube to induce high rates of volatile release. Wardle et al. (2003) suggested that the volatiles may act as an alarm pheromone or as chemical defenses against predators; however, no experiments were carried out to test these hypotheses.

The objectives of this study were to (1) induce releases of volatiles from both sexes of $L$. hesperus and identify the compounds and their relative amounts, (2) compare these to amounts in solvent extracts of individual insects, and (3) test volatile compounds for intraspecific alarm functions and for defensive functions against two species of ants. A further objective was to look for compounds unique to females that might be sex pheromone components. 


\section{Methods and Materials}

Induced Release of Defensive Chemicals from Adult Tarnished Plant Bugs and Behavioral Effects

Unless otherwise stated, L. hesperus (collected from Maricopa, AZ, USA) was reared in the laboratory on green beans and synthetic diet (Rodriguez-Saona et al., 2002; Blackmer et al., 2004). Sexes were separated by the presence or absence of an ovipositor groove. Volatile chemicals from male and female L. hesperus were collected from the headspace by solidphase microextraction (SPME). Individual L. hesperus were chilled so that they did not release volatiles under stress when transferred to 2-ml glass vials with Teflon liners with a 0.5-mm hole, allowing insertion of the SPME needle. A $65-\mu \mathrm{m}$ Carbowax-divinylbenzene SPME fiber (Supelco, Bellefonte, PA, USA) was inserted into the vials for $10 \mathrm{~min}$ to collect background volatiles that were then desorbed in the $\mathrm{GC}-\mathrm{MS}$ injection port at $250^{\circ} \mathrm{C}$ for $5 \mathrm{~min}$. In some experiments, a vial was opened and forceps were used to grab the leg of an adult for about $10 \mathrm{sec}$ (molestation) to induce defensive emissions, the vial was recapped, and volatiles were collected for 10 or $120 \mathrm{sec}$ by SPME.

Gas chromatography-MS analysis of volatiles collected on SPME fibers was carried out with a Varian $3900 \mathrm{GC}$ with a $30 \mathrm{~m} \times 0.25 \mathrm{~mm}$ ID column coated with $0.25 \mu \mathrm{m}$ CP-Sil 8 CB (Varian CP5860). Helium carrier gas was programmed for constant flow $(1.2 \mathrm{ml} / \mathrm{min})$. The injection at $250^{\circ} \mathrm{C}$ was splitless for $5 \mathrm{~min}$ (then split 20:1), whereas the oven/column temperature was held at $40^{\circ} \mathrm{C}$ during the same period before increasing at $5^{\circ} \mathrm{C} / \mathrm{min}$ to $180^{\circ} \mathrm{C}$. Thereafter, temperature increased at $20^{\circ} \mathrm{C} / \mathrm{min}$ to $250^{\circ} \mathrm{C}$ and was held for $5 \mathrm{~min}$. Compounds in GC effluents were analyzed with a Varian Saturn 2100D MS using the NIST02 and Wiley7 spectral libraries and comparison to commercial standards (all $>98 \%$ purity, Aldrich Chemical Co. and Bedoukian Research, Danbury CT, USA), except (E)-4-oxo-2-hexenal ( $>98 \%$, synthesized by H.D. Pierce Jr. and provided by R. Gries, Burnaby, B.C., Canada) and pentyl butyrate (previously identified by Ho and Millar, 2002).

In bioassay experiments, harvester ants, Pogonomyrmex rugosus Emery, and native fire ants, Solenopsis xyloni McCook, from Phoenix, AZ, were placed in 2-ml vials with an adult bug until the ant initiated an attack, whereupon SPME collection was performed for 1$2 \mathrm{~min}$. The behavioral and lethal effects of saturated vapors of hexyl butyrate $(50 \mu \mathrm{l}$ in $125-\mathrm{ml}$ closed bottle) or $0.5 \mu \mathrm{l}$ direct applications of hexyl butyrate on P. rugosus were observed every $30 \mathrm{~min}$ for $1 \mathrm{~min}$ over an 8-hr period. Adults of L. hesperus grasped with forceps were presented within a few millimeters of resting L. hesperus nymphs and adults for several seconds to determine if any alarm behavior could be induced.

\section{Quantification of Volatile Chemicals in Adult Tarnished Plant Bugs}

Adult L. hesperus reared in the laboratory or collected on September 8, 2004, in Maricopa, $\mathrm{AZ}$, from the field (wild) were extracted individually, with $100 \mu \mathrm{l}$ pentane with an internal standard of ethyl heptanoate $\left(1 \mathrm{ng} / \mu \mathrm{l}\right.$, Aldrich). Adults were cooled to $3^{\circ} \mathrm{C}$ and dropped into solvent contained in a $100-\mu \mathrm{l}$ conical vial and crushed with a blunt, nickel-plated tapestry needle (Prym-Dritz Corp., Spartanburg, SC, USA). The solvent was immediately sucked off the mashed insect and placed in a new vial and analyzed within a few days by GC-MS. Leaving the crushed cadaver in solvent caused degradation of $(E)$-4-oxo-2-hexenal (see Results). The metathoracic glands of three 10-d-old individuals of each sex were dissected under water and extracted as above. The column and temperature program used for analysis 
of solvent extracts were the same as for SPME above, but the flow was splitless for $0.75 \mathrm{~min}$ before being split $60: 1$ for $4.25 \mathrm{~min}$ (thereafter 20:1) and was maintained an additional $10 \mathrm{~min}$ at $250^{\circ} \mathrm{C}$.

For quantification of various volatile chemicals in solvent extracts of $L$. hesperus, the total ion chromatogram peak areas at the respective retention times were compared with areas of the internal standard (ethyl heptanoate) and adjusted for the MS response factor sensitivities of identified compounds. The MS chromatogram areas of the three major compounds, hexyl butyrate, $(E)$-2-hexenyl butyrate, and $(E)$-4-oxo-2-hexenal from adults were usually large and needed correction for nonlinear MS responses. This was carried out by multiplying the peak areas by a correction function $(Y)$ before comparison to the internal standard. This function was determined by GC-MS for a concentration curve of each compound $(0.1,1,10,100,1000 \mathrm{ng} / \mu \mathrm{l})$ and regressing $X$ (observed MS peak area at each amount) with $Y$ (predicted peak area from linear extrapolation of the area for $1 \mathrm{ng}$ times the number of nanograms injected divided by $X$ ) to obtain a best-fitting function (e.g., for hexyl butyrate: $\left.Y=0.862+0.0002593 X^{0.5}, R^{2}=0.995\right)$. Differences between means of chemical amounts were analyzed by $t$-tests, and linear and nonlinear regressions were performed on scatter plots of individual L. hesperus weights or adult age after last instar ecdysis vs. amounts of volatile compounds (Sokal and Rohlf, 1995; Statistica 5.1 by StatSoft, Inc.).

To determine the amounts of volatile compounds in each sex as they matured sexually (Strong et al., 1970), a large cohort of newly emerged adults from the laboratory colony were separated by sex and kept separately until extraction. In other experiments, adults of both sexes were kept together for known times until extraction. Individual weights of 16 males and 16 females from the laboratory colony were taken on a Mettler balance (precision of $0.1 \mathrm{mg}$ ) and each was extracted to determine if volatile compound amounts varied with weight.

\section{Initial Discharge Percentage of Volatile Chemicals}

The initial discharge percentage (IDP) is defined as the percentage of volatile chemical secretion that is discharged from an insect due to an initial molestation stimulus. Because extraction destroys the insects, a group of adults was split and individuals of one cohort were extracted for volatiles to obtain a mean $(\bar{A})$, and this was compared with the mean of the other cohort $(\bar{B})$ after they had discharged chemicals due to molestation. SPME collection ( $2 \mathrm{~min}$, described above) and GC-MS were used to verify whether members of group B released volatiles before their extraction. After SPME, the molested adults were removed from the $2-\mathrm{ml}$ vial and aired out for $12 \mathrm{~min}$ before extraction. The volatile secretion was defined as the sum of amounts of hexyl butyrate and $(E)$-2-hexenyl butyrate because the latter did not fully separate by GC on the column used. Because age plays a role in amounts of volatiles, 10-d-old males and females of the two cohorts were extracted to determine the IDP for volatile compounds:

$$
\mathrm{IDP}=\frac{\bar{A}-\bar{B}}{\bar{A}} \cdot 100
$$

Amounts of Volatile Compounds and their Cross-Correlations

In addition to the three major volatiles, six additional compounds were commonly identified in adults older than $2 \mathrm{~d}$ of age. Correlation matrices (Statistica) were carried out 
on the quantified amounts of the nine compounds in individual males and females from the three major experiments (maturation, IDP, and weight variation).

\section{Results}

Induced Release of Volatiles from Adult Tarnished Plant Bugs and Behavioral Effects

Resting L. hesperus adults did not release SPME-detectable amounts of any volatiles in 10 -min periods $(N=6)$. However, briefly grabbing one of the legs of an adult bug with fine forceps induced the immediate discharge of volatile compounds as determined by SPME and GC-MS ( $N=8$ of each sex, IPD experiment). Relative amounts of the compounds hexyl butyrate, $(E)$-4-oxo-2-hexenal, and $(E)$-2-hexenyl butyrate released were estimated from SPME peak areas corrected for MS responses and normalized, yielding $100 \pm 13 \%$ $( \pm S E), 44 \pm 9 \%$, and $4 \pm 0.5 \%$, respectively, from females and $83 \pm 18 \%, 37 \pm 9 \%$, and $3 \pm 0.5 \%$ from males.

Pogonomyrmex rugosus $(N=4)$ and $S$. xyloni $(N=3)$ ants placed individually with a bug in 2-ml vials usually spent a few minutes in searching/escape movements before opening their mandibles and grasping the bug in an attack. Immediately after this, the ant jerked its head away and violently began running. Thereafter, SPME for $10 \mathrm{sec}$ showed high concentrations of the volatile components of the adult bug (similar to grabbing with forceps above) as well as smaller amounts of an alarm pheromone from P. rugosus (4methyl-3-heptanone; McGurk et al., 1966). The ants and L. hesperus were removed from the vials after SPME and none appeared adversely affected. However, one P. rugosus after being irritated by the defensive secretion repeatedly attacked and killed the bug, and then the ant's movements became spasmodic. This ant was removed a few minutes later and recovered but had permanent damage to its antennae as evidenced by lack of movement. Two S. xyloni ants that attacked L. hesperus were left in the vials and died within $4 \mathrm{hr}$, whereas the adult bugs survived for more than $15 \mathrm{hr}$.

Pogonomyrmex rugosus ants exposed singly in $125-\mathrm{ml}$ bottles to saturated vapors of hexyl butyrate for $8 \mathrm{hr}$ showed no behavioral or toxic effects compared with a control group in similar bottles $(N=6$ each group). However, topical application of $0.5 \mu l$ of neat hexyl butyrate caused violent escape behaviors by the ant that within seconds turned into spasms $(N=6)$. All treated ants recovered apparently normal motor behavior within an hour. None of the $L$. hesperus adults $(N=5)$ held by forceps and presented within a few millimeters of resting nymphs and adults elicited any movement or alarm behavior ( $N=8$ for each group for each held adult). All five forceps-held adults discharged average amounts of butyrates as indicated by SPME and solvent extraction.

\section{Quantification of Volatiles in Adult Tarnished Plant Bugs}

When adult $L$. hesperus were placed in pentane, they released a fluid as seen by refractive changes. (E)-4-Oxo-2-hexenal amounts $(Y)$ declined rapidly with time $(X)$ in the solvent extracts (e.g., $13.9 \mu \mathrm{g}$ initially, $19 \%$ left after $75 \mathrm{~min}, 0.4 \%$ left after $4 \mathrm{hr}$ ) when the crushed cadaver remained in the solvent $\left(Y=e^{3-0.24 \sqrt{ } x}, R^{2}>0.99, N=4\right)$. This also caused a more gradual loss over several weeks of hexyl butyrate and $(E)$-2-hexenyl butyrate (as well as the internal standard). The loss of (E)-4-oxo-2-hexenal occurred rapidly in pentane as well as in diethyl ether and acetone. In the same cadaver extract, $\gamma$-caprolactone 
[5-ethyldihydro-2-(3H)-furanone] was not detected initially but accumulated over time $\left(Y=-0.002+0.00085 X, R^{2}>0.99, N=4\right.$; e.g., $0.22 \mu \mathrm{g}$ after $4 \mathrm{hr}, 1.23 \mu \mathrm{g}$ after $\left.24 \mathrm{hr}\right)$. In contrast, if the solvent extract was sucked off the macerated bug and placed in a new vial, then (E)-4-oxo-2-hexenal and the esters were stable in solvent for weeks and $\gamma$-caprolactone did not accumulate. Using the decanting method, sample extracts were usually analyzed within a day or two of preparation to ensure the accuracy of quantification. The solvent extraction was efficient because a second extraction with $100 \mu \mathrm{l}$ pentane performed on a few individuals recovered $<1 \%$ of the material recovered in the first extraction.

Logarithmic regression of amounts of (E)-4-oxo-2-hexenal produced in L. hesperus of different adult ages showed nearly identical curves for males and females (female: $Y=1.19+1.54 \ln X, R^{2}=0.72, P<0.001, N=13$; male $Y=1.15+1.56 \ln X, R^{2}=$ $0.69, P<0.001, N=13$; Fig. 1). Pooling data of adults aged 8 to $19 \mathrm{~d}$ gave a mean of $5.6 \mu \mathrm{g}$ per male and $5.1 \mu \mathrm{g}$ per female of $(E)$-4-oxo-2-hexenal (not significantly different, $t=-0.39, d f=39, P=0.70)$. However, females produced more hexyl butyrate $\left(Y=4+6.64 \ln X, R^{2}=0.67, P<0.001\right)$ and $(E)$-2-hexenyl butyrate $(Y=0.44+$ $\left.0.58 \ln X, R^{2}=0.77, P<0.001\right)$ than males $\left(Y=3.3+3.52 \ln X, R^{2}=0.77, P<\right.$ $0.001 ; Y=0.29+0.20 \ln X, R^{2}=0.58, P=0.003$, respectively). Pooling data from days 8 to 19 gave a mean of $22 \mu \mathrm{g}$ hexyl butyrate per female, significantly more than the $13 \mu \mathrm{g}$ per male $(t=2.39, d f=39, P=0.02)$. Females had a mean of $1.9 \mu \mathrm{g}(E)$-2-hexenyl butyrate, significantly more than the $0.8 \mu \mathrm{g}$ in males $(t=3.77, d f=39, P<0.001)$.

The amounts of $(E)$-4-oxo-2-hexenal and the pooled butyrates [hexyl and $(E)$-2-hexenyl butyrate] increased in relation to fresh weight of females reared in the laboratory (Fig. 2). In wild females, linear regression gave positive slopes but none were significant $(P>0.05)$, although hexyl butyrate had an $R^{2}=0.63(N=6)$. In laboratory females, only the slope of (E)-4-oxo-2-hexenal was significant $(P=0.01)$ with an $R^{2}=0.37$. Combining the two butyrates (Fig. 2), because they did not separate fully by GC, gave a regression for laboratory females of $\left.Y=-9.47+1.44 X, R^{2}=0.18, N=16\right)$, suggesting a weak correlation and positive slope, although not significant $(P=0.1)$. The amounts of the volatile compounds in males showed no relationship with weight and had a high variation similar to females (Fig. 2). All regressions of male weight and amounts of volatiles (wild $N=10$, laboratory $N=16$ ) gave $R^{2}$ values of $<0.01$, and none of the slopes were significantly different from 0 (Fig. 2).

No significant differences in body weight were found between laboratory and wild males, but the mean weight of laboratory females was greater than wild females $(t=3.84, d f=20$, $P=0.001$; Table 1). Laboratory females weighed more than laboratory males $(t=15.19$, $d f=30, P<0.001)$ and wild females weighed more than wild males $(t=4.93, d f=14, P<$ $0.001)$. No significant differences in the amounts of $(E)$-4-oxo-2-hexenal, hexyl butyrate, and $(E)$-2-hexenyl butyrate were found between sexes of laboratory or wild adults (Table 1 , Fig. 2), or between laboratory and wild adults of the same sex, except for wild males that had less (E)-4-oxo-2-hexenal than laboratory males $(t=2.39, d f=24, P=0.025)$. Metathoracic glands dissected from laboratory males and females had comparable amounts of volatiles to those in whole bodies from other experiments (Tables 1 and 2).

\section{Initial Discharge Percentage of Volatiles}

Females had an IDP of $84 \%$ for $(E)-4$-oxo-2-hexenal and $59 \%$ for the combination of hexyl butyrate and (E)-2-hexenyl butyrate (Fig. 3). Males had an IDP of $66 \%$ for $(E)-4$-oxo-2- 
Fig. 1 Amount of volatile compounds in male and female $L$. hesperus in relation to age in days after their final ecdysis (laboratory colony, March 2003). Each point and brackets represent a mean $\pm \operatorname{SE}(N=4)$
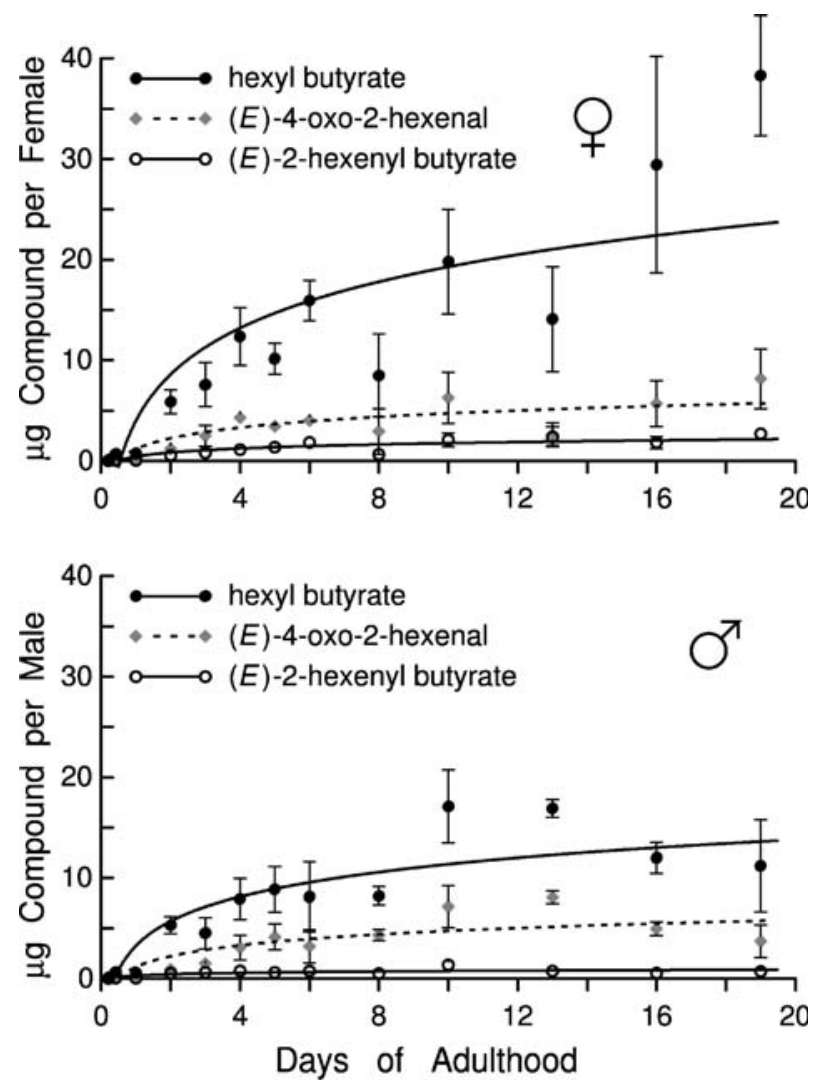

hexenal and 32\% for hexyl butyrate plus (E)-2-hexenyl butyrate. Molested/discharged males and females contained lower amounts of the major volatiles than the nonmolested cohort, but only $(E)$-2-hexenyl butyrate in molested males $(t=2.97, d f=14, P=0.010)$, and only hexyl butyrate in molested females $(t=2.44, d f=14, P=0.028)$ were significantly less. Of the six minor constituents, most were less in molested males: $(E)-2-$ hexenal $(20 \%$, as percentage of unmolested in Table 2, IDP experiment), 1-hexanol (45\%), compound X (49\%), pentyl butyrate (35\%), and (Z)-3-hexenyl butyrate (50\%). However, levels of hexyl acetate $(130 \%)$ were higher in molested males. Compound X eluted at $12.15 \mathrm{~min}$ and had MS major fragments $(\mathrm{m} / \mathrm{z})$ of 56, 57 (base), 85, and 86. In females, compound X (25\%), pentyl butyrate (36\%), (Z)-3-hexenyl butyrate (30\%), and hexyl acetate $(70 \%)$ were reduced after molestation, whereas $(E)$-2-hexenal $(237 \%)$ and 1-hexanol (234\%) increased. However, of the minor constituents, only pentyl butyrate and (Z)-3hexenyl butyrate were significantly less after discharge in both sexes (all $P<0.01$ ).

\section{Amounts of Volatiles and their Cross-Correlations}

In addition to the three major volatiles presented earlier, six additional minor compounds were quantified in adults ( $8 \mathrm{~d}$ or older) from the maturation, IDP, and weight experiments 
Fig. 2 Amounts of volatile compounds in relation to fresh body weight of 10-d-old adult male and female $L$. hesperus reared in the laboratory (August 2004, $N=16$ each sex)
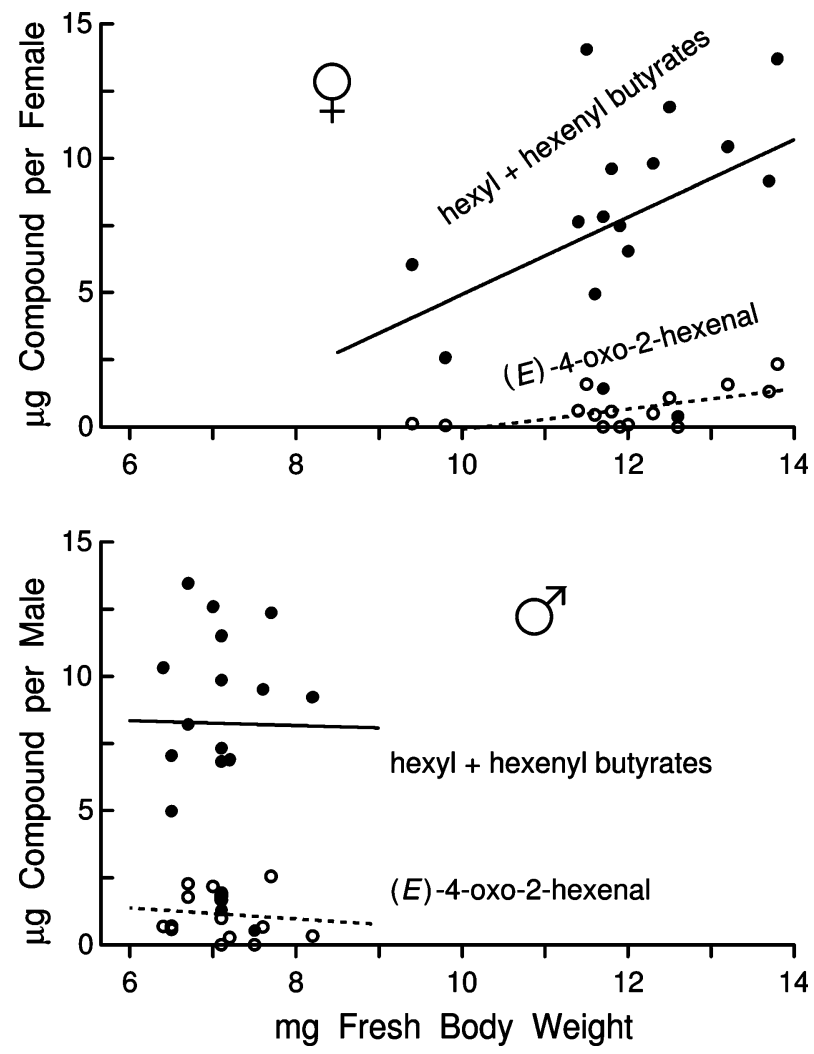

presented above to investigate biosynthetic aspects (Table 2). As adults aged, the ratios of the six minor components to the three major ones remained relatively constant (data not shown). No compounds were detected in 5-hr-old adults, but by $10 \mathrm{hr}$ of age, $(E)-2-$ hexenal, 1-hexanol, (E)-4-oxo-2-hexenal, hexyl acetate, (Z)-3-hexenyl butyrate, hexyl butyrate, and $(E)$-2-hexenyl butyrate were evident in small amounts. By $1 \mathrm{~d}$ of age, in addition to these compounds, males had pentyl butyrate and an unidentified compound $\mathrm{X}$,

Table 1 Mean body weights and mean amounts of the major volatile components of laboratory and wild $L$. hesperus adults, and mean component amounts in methathoracic glands of laboratory adults

\begin{tabular}{|c|c|c|c|c|}
\hline Source & $\begin{array}{l}\text { Mean body } \\
\text { weight } \\
(\mathrm{mg} \pm \mathrm{SE})\end{array}$ & $\begin{array}{l}(E)-4-O x o-2- \\
\text { hexenal } \\
(\mu g \pm S E)\end{array}$ & $\begin{array}{l}\text { Hexyl butyrate } \\
(\mu \mathrm{g} \pm \mathrm{SE})\end{array}$ & $\begin{array}{l}(E) \text {-2-Hexenyl } \\
\text { butyrate } \\
(\mu \mathrm{g} \pm \mathrm{SE})\end{array}$ \\
\hline $\begin{array}{l}\text { Laboratory male } \\
\qquad(N=16)\end{array}$ & $7.09 \pm 0.12$ & $1.15 \pm 0.21$ & $7.84 \pm 0.90$ & $0.40 \pm 0.05$ \\
\hline $\begin{array}{l}\text { Laboratory female } \\
\qquad(N=16)\end{array}$ & $11.93 \pm 0.29$ & $0.64 \pm 0.18$ & $7.22 \pm 0.95$ & $0.50 \pm 0.08$ \\
\hline Wild male $(N=10)$ & $7.45 \pm 0.23$ & $0.41 \pm 0.19$ & $5.16 \pm 1.17$ & $0.47 \pm 0.13$ \\
\hline Wild female $(N=6)$ & $9.77 \pm 0.48$ & $0.90 \pm 0.44$ & $9.61 \pm 2.47$ & $0.61 \pm 0.16$ \\
\hline Male gland $(N=3)$ & - & $2.62 \pm 1.06$ & $5.83 \pm 1.47$ & $0.56 \pm 0.17$ \\
\hline Female gland $(N=3)$ & - & $2.59 \pm 0.48$ & $6.22 \pm 1.13$ & $0.59 \pm 0.16$ \\
\hline
\end{tabular}




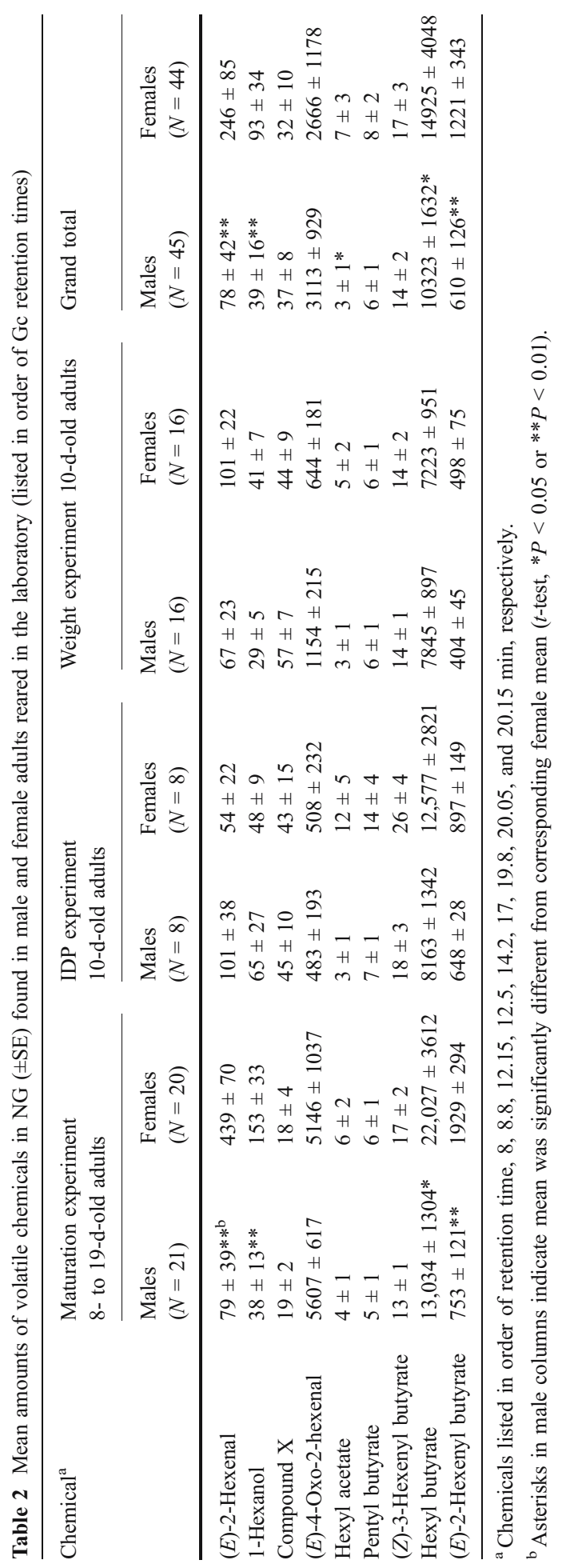


Fig. 3 Mean amounts of volatile compounds in cohort groups of male and female $L$. hesperus after being molested (grasping a leg in forceps) to induce discharge of volatiles as detected by SPME, or not molested (control). Lines above bars represent $+\mathrm{SE}$ (bugs from laboratory colony, June $2004, N=8$ for each bar)

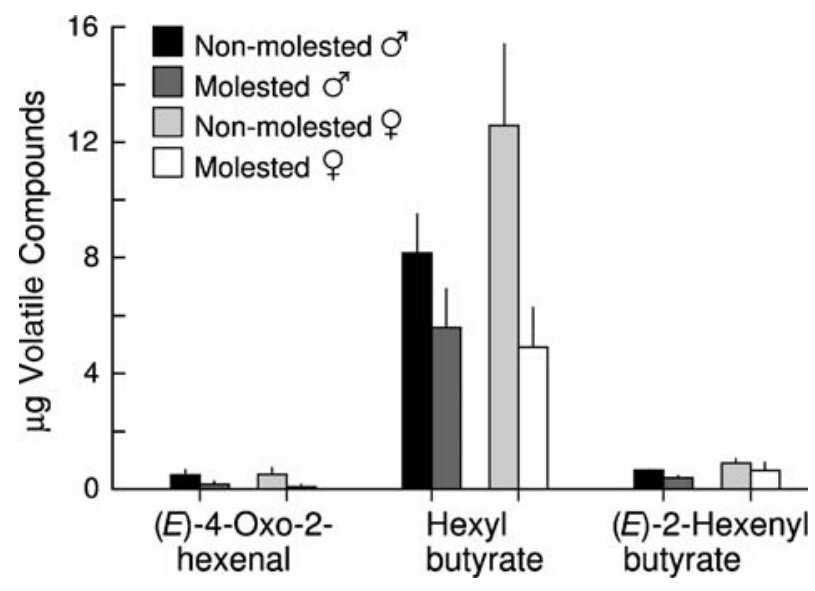

whereas by day 2 , both sexes had all compounds in Table 2 . A comparison of means of the nine compounds in adult males vs. females indicated no significant differences between the sexes for compound X, $(E)$-4-oxo-2-hexenal, pentyl butyrate, and (Z)-3-hexenyl butyrate. Significant differences were found for $(E)$-2-hexenal, 1-hexanol, hexyl acetate, hexyl butyrate, and (E)-2-hexenyl butyrate, with females having more of each of these compounds on average (Table 2).

The correlation matrices of nine compounds in the defensive secretion of males and females (Table 3$)$ gave a higher number of significant correlations $(P<0.05)$ among 36 possible pairings for each sex than expected of a null hypothesis. Of these pairings, 12 were significant for males (33\%) and 19 for females $(53 \%)$, much higher than the expected two correlations for each sex based on a 5\% level of significance. All of the significant correlations were positive, suggesting that many of the nine compounds were involved in biosynthesis of the defensive secretion. There were 25 corresponding correlations for males and females that were similar in regard to significance $(69.4 \%)$ and 11 cases where the significance levels differed between the sexes. The two major butyrates and (E)-4-oxo-2hexenal were significantly correlated between themselves in each sex. By pooling males and females, significant positive correlations were found between all possible comparisons of 1-hexanol, $(E)$-2-hexenal, $(E)$-4-oxo-2-hexenal, hexyl butyrate, and $(E)$-2-hexyl butyrate (data not shown).

\section{Discussion}

Wardle et al. (2003) suggested that the function of hexyl butyrate and other volatiles released by agitated L. lineolaris could be either as an alarm pheromone or as defensive allomones, but no experiments were carried out with predators. In the present study, alarm behavior was not elicited in nymphs or adults of $L$. hesperus when presented with conspecifics releasing defensive secretions. Alarm pheromones are likely to evolve only when related individuals live in aggregations, such as with social insects or aphid colonies (Byers, 2005). It is possible that unrelated individuals could exploit defensive emissions of others as a warning of predatory danger, but this apparently has not evolved in L. hesperus. I also exposed adults of $L$. hesperus to two native species of ants found in fields near infestations of the bug. The adult bugs attacked by ants released a volatile secretion composed mainly of hexyl butyrate, $(E)$-4-oxo-2-hexenal, and (E)-2-hexenyl butyrate that 
Table 3 Correlation matrix of nine L. hesperus volatile compounds in each sex

\begin{tabular}{|c|c|c|c|c|c|c|c|c|}
\hline Compounds $^{\mathrm{a}}$ & $\begin{array}{l}(E)-2- \\
\text { Hexenal }\end{array}$ & $\begin{array}{l}\text { 1- } \\
\text { Hexanol }\end{array}$ & $\begin{array}{l}\text { Compound } \\
\mathrm{X}\end{array}$ & $\begin{array}{l}(E)-4-O x o- \\
\text { 2-hexenal }\end{array}$ & $\begin{array}{l}\text { Hexyl } \\
\text { acetate }\end{array}$ & $\begin{array}{l}\text { Pentyl } \\
\text { butyrate }\end{array}$ & $\begin{array}{l}(Z)-3- \\
\text { Hexenyl } \\
\text { butyrate }\end{array}$ & $\begin{array}{l}\text { Hexyl } \\
\text { butyrate }\end{array}$ \\
\hline \multicolumn{9}{|l|}{ Males } \\
\hline 1-Hexanol & $0.66^{* b}$ & & & & & & & \\
\hline Unknown X & 0.02 & 0.08 & & & & & & \\
\hline $\begin{array}{r}(E)-4-O x o- \\
\text { 2-hexenal }\end{array}$ & $-0.14^{\mathrm{c}}$ & $-0.09^{\mathrm{c}}$ & -0.24 & & & & & \\
\hline $\begin{array}{l}\text { Hexyl } \\
\text { acetate }\end{array}$ & $0.44 *^{\mathrm{c}}$ & 0.15 & -0.04 & 0.04 & & & & \\
\hline $\begin{array}{l}\text { Pentyl } \\
\text { butyrate }\end{array}$ & -0.18 & -0.08 & $0.29^{c}$ & 0.15 & 0.09 & & & \\
\hline $\begin{array}{l}(Z)-3- \\
\text { Hexenyl } \\
\text { butyrate }\end{array}$ & $-0.08^{\mathrm{c}}$ & -0.16 & $0.40 *$ & $0.24^{\mathrm{c}}$ & 0.12 & $0.75 *$ & & \\
\hline $\begin{array}{l}\text { Hexyl } \\
\text { butyrate }\end{array}$ & $-0.04^{\mathrm{c}}$ & $0.09^{c}$ & -0.00 & $0.81 *$ & 0.15 & $0.50^{*}$ & $0.55^{*}$ & \\
\hline $\begin{array}{l}(E)-2- \\
\text { Hexenyl } \\
\text { butyrate }\end{array}$ & $0.48^{*}$ & $0.44 *$ & -0.08 & $0.47 *$ & $0.33 * \mathrm{c}$ & $0.21^{\mathrm{c}}$ & $0.18^{\mathrm{c}}$ & $0.60 *$ \\
\hline \multicolumn{9}{|l|}{ Females } \\
\hline 1-Hexanol & $0.47^{*}$ & & & & & & & \\
\hline Unknown X & -0.02 & -0.11 & & & & & & \\
\hline $\begin{array}{l}(E)-4-O x o- \\
\text { 2-hexenal }\end{array}$ & $0.80^{* \mathrm{c}}$ & $0.48^{* \mathrm{c}}$ & 0.10 & & & & & \\
\hline $\begin{array}{l}\text { Hexyl } \\
\text { acetate }\end{array}$ & $0.03^{c}$ & -0.03 & 0.20 & 0.20 & & & & \\
\hline $\begin{array}{l}\text { Pentyl } \\
\text { butyrate }\end{array}$ & 0.13 & -0.03 & $0.62 * \mathrm{c}$ & 0.23 & 0.07 & & & \\
\hline $\begin{array}{l}(Z)-3- \\
\text { Hexenyl } \\
\text { butyrate }\end{array}$ & $0.36^{* \mathrm{c}}$ & 0.07 & $0.58 *$ & $0.44 * \mathrm{c}$ & 0.22 & $0.87 *$ & & \\
\hline $\begin{array}{l}\text { Hexyl } \\
\text { butyrate }\end{array}$ & $0.75^{* \mathrm{c}}$ & $0.44^{* \mathrm{c}}$ & 0.21 & $0.85^{*}$ & 0.09 & $0.45^{*}$ & $0.67 *$ & \\
\hline $\begin{array}{l}(E)-2- \\
\text { Hexenyl } \\
\text { butyrate }\end{array}$ & $0.87 *$ & $0.35^{*}$ & 0.04 & $0.74 *$ & $0.05^{\mathrm{c}}$ & $0.33 * \mathrm{c}$ & $0.52 * \mathrm{c}$ & $0.80^{*}$ \\
\hline
\end{tabular}

${ }^{\mathrm{a}} N=45$ males, 44 females.

${ }^{\mathrm{b}}$ Correlations with an asterisk are significant at $P<0.05$.

${ }^{\mathrm{c}}$ Sexes were different in terms of significance.

apparently caused agitated movements and avoidance by the predator. These reactions were probably the result of direct contact with the secretion because application of hexyl butyrate (at high doses) elicited violent reactions, whereas ants showed no behavioral changes or toxicological effects during 8-hr exposure to saturated vapors of the compound. Stink bugs (Heteroptera: Pentatomidae) release similar volatile compounds such as (E)-2-decenyl acetate and (E)-2-decenal that deter feeding by birds and lizards (Krall et al., 1999).

Wardle et al. (2003) collected volatiles from disturbed $L$. lineolaris females for $1 \mathrm{hr}$ on Porapak Q and determined that they released $23.6 \mu \mathrm{g}$ of hexyl butyrate, $8 \mu \mathrm{g}$ of $(E)-2-$ hexenyl butyrate, $1.8 \mu \mathrm{g}$ of $(E)$-4-oxo-2-hexenal, $0.7 \mu \mathrm{g}$ of $(E)$-2-hexenal, and $0.4 \mu \mathrm{g}$ of 1 - 
hexanol per bug-hour $(100 \%, 34 \%, 7.5 \%, 3.2 \%, 1.7 \%$, respectively). These compounds were also released in the present study from L. hesperus, but because the methods of the two studies differ, the compound ratios are not comparable. In this study, SPME exposure for 2 min was used to collect compounds in the vapor phase in which the more volatile $(E)$ hexenal, 1-hexanol, and (E)-4-oxo-2-hexenal should have volatilized more completely from the insect surface in the first few minutes after discharge than less volatile components such as hexyl butyrate and $(E)$-2-hexenyl butyrate. Thus, it seems more appropriate to compare the extracted amounts of females in this study $(100 \%, 8 \%, 18 \%, 2 \%, 1 \%$, respectively; Table 2) and assume they are discharged in the same proportions as would be collected by absorbent over a 1-hr period. Ho and Millar (2002) found all of the major and minor compounds (Aldrich et al., 1988) in aerations of macerated females as those presented here but in somewhat different ratios $(100 \%, 4.5 \%, 1 \%, 10 \%$, and $10 \%)$, possibly caused by degradation of some components during the 22-hr aerations. They also showed that heptyl butyrate placed on bugs was hydrolyzed to 1-heptanol. Significant positive correlations among many of the defensive components (Table 3) suggest that they are involved in biosynthesis and hydrolysis in an equilibrium that could be altered during aeration of macerated bugs (Ho and Millar, 2002) or even during solvent extractions if the bug remains to provide catalytic sites. The present experiments show that quantification is optimized by immediate decanting of solvent from the macerated bug followed by analysis within $2 \mathrm{~d}$.

The most significant difference between studies was the low percentage of $(E)$-4-oxo-2hexenal $(1.2 \%$ in females and $0.05 \%$ in males) found by Ho and Millar (2002) compared with the $18 \%$ and $30 \%$ in the present study (Table 2). Also, they did not detect this compound in pentane extracts of metathoracic glands, rather only hexyl butyrate, $(E)$-2hexenyl butyrate, $(E)$-2-hexenal, and 1-hexanol. However, in gland extracts of both sexes, the author found large amounts $(0.5$ to $6 \mu \mathrm{g})$ of $(E)$-4-oxo-2-hexenal, hexyl butyrate, and (E)-2-hexenyl butyrate with small amounts (4 to $30 \mathrm{ng}$ ) of 1-hexanol, compound X, pentyl butyrate, and (Z)-3-hexenyl butyrate. Earlier, Aldrich et al. (1988) found small amounts of (E)-4-oxo-2-hexenal in female metathoracic glands but detected none in males. Again, the most probable explanation for the discrepancy is that $(E)$-4-oxo-2-hexenal breaks down rapidly in solvent when the macerated gland or whole bug is present. Therefore, $(E)$-4-oxo2-hexenal seems to be more important to the blend of defensive components than suggested from earlier data (Aldrich et al., 1988; Ho and Millar, 2002). Studies of semiochemical identification could miss important compounds if catalytic sites in the biological material remain active in solvent to alter chemical structures before analyses are carried out. Conversely, generation of artifacts through prolonged exposure of extracts to tissues, such as the production of gamma-caprolactone in this study, may complicate analyses.

Ho and Millar (2002) did not ascribe any biological function to the volatiles released by L. hesperus other than to suggest that one or more could serve as components of a sex or aggregation pheromone. However, they did not find any differences between the sexes that would suggest sex pheromone components nor were any two-way blends attractive in the field. The present study did not find any significant differences between the sexes either, but does demonstrate the defensive role of the secretions. The volatile components in recently eclosed adults are negligible but then increase with age, in agreement with results for hexyl butyrate in Ho and Millar (2002, their Fig. 1). Several studies (Scales, 1968; Strong et al., 1970; Graham, 1987, 1988; McLaughlin, 1996) provided convincing evidence that virgin females are attractive to males, but identification of $L$. hesperus sex pheromone components has so far been elusive for a number of possible reasons as discussed in Ho and Millar (2002). 
The quantities of the hexyl and (E)-2-hexenyl butyrates and (E)-4-oxo-2-hexenal increased with an increase in weight of laboratory-reared females (Fig. 2). These 10-d-old females had mated with males and were producing eggs as observed during maceration in solvent. In contrast, male size did not appear to affect compound amounts (Fig. 2). It is unknown why young adults contain no defensive allomones for about $1-2 \mathrm{~d}$ after molting (Fig. 1) and, thus, are more vulnerable to predators than adults. Resources are probably needed more for maturation processes during this time than for biosynthesis of allomones.

Relatively few studies have reported increased semiochemical content as a function of body weight or size. Amounts of aggregation pheromone components of a bark beetle (Birgersson et al., 1988) and male butterfly courtship pheromone components (Sappington and Taylor, 1990) were not correlated with weight or size (0-3\% of variation explained). Pureswaran and Borden (2003) found no relationship between body size and aggregation pheromone components of mountain pine beetles but did find a positive relationship for antiaggregation components. Byers (2005) found that as first instar to adult cotton aphid weights increased over a 60 -fold range, the amounts of alarm pheromone, $(E)-\beta$-farnesene, found in all stages were positively related $(66 \%$ of the variation in pheromone amounts explained by increases in weight). Lygus hesperus produces microgram quantities of defensive allomones compared with nanogram amounts of pheromones in bark beetles and aphids (Birgersson et al., 1988; Pureswaran and Borden, 2003; Byers, 2005). Thus, results for L. hesperus suggest that in insects producing large amounts of defensive allomones, the costs can be enough to manifest a positive relationship with size even in adults that vary less in weight compared with all developmental stages (e.g., aphids).

Acknowledgments I thank Dan Langhorst and LeAnne Elhoff for maintaining the colonies of tarnished plant bugs; LeAnne Elhoff for technical assistance; and Jackie Blackmer, Hollis Flint, and the Journal's review process for helping improve the manuscript.

\section{References}

Aldrich, J. R., Lusby, W. R., Kochansky, J. P., Hoffmann, L. T., Wilson, F. G., and Zalom, F. G. 1988. Lygus bug pheromones, vis-à-vis stink bugs. Proceedings Beltwide Cotton Production Research Conferences. pp. 213-216.

Birgersson, G., SChlyter, F., and BergStröM, G. 1988. Individual variation in aggregation pheromone content of the bark beetle, Ips typographus. J. Chem. Ecol. 14:1737-1761.

Blackmer, J. L., Rodriguez-Saona, C., Byers, J. A., Shope, K. L., and Smith, J. P. 2004. Behavioral response of Lygus hesperus to conspecifics and headspace volatiles of alfalfa in a Y-tube olfactometer. J. Chem. Ecol. 30:1547-1564.

BYERS, J. A. 2005. A cost of alarm pheromone production in cotton aphids, Aphis gossypii. Naturwissenschaften 92:69-72.

Clancy, D. W. and Pierce, H. D. 1966. Natural enemies of some Lygus bugs. J. Econ. Entomol. 59:853858.

Debolt, J. W. and Patana, R. 1985. Lygus hesperus, pp 329-338, in P. Singh and R. F. Moore (eds.). Handbook of Insect Rearing, Vol. 1. Elsevier, New York.

GrahaM, H. M. 1987. Attraction of Lygus spp. males by conspecific and congeneric females. Southwest. Entomol. 12:147-154.

Graham, H.M. 1988. Sexual attraction of Lygus hesperus Knight. Southwest. Entomol. 13:31-37.

Ho, H.-Y. and MillaR, J. G. 2002. Identification, electroantennogram screening, and field bioassays of volatile chemicals from Lygus hesperus Knight (Heteroptera: Miridae). Zool. Studies 41:311-320.

Kelton, L. A. 1975. The Lygus bugs (genus Lygus Hahn) of North America (Heteroptera: Miridae). Mem. Entomol. Soc. Can. 95:1-101.

Krall, B. S., Bartelt, R. J., Lewis, C. J., and Whitman, D. W. 1999. Chemical defense in the stink bug Cosmopepla bimaculata. J. Chem. Ecol. 25:2477-2494. 
McGurk, D. J., Frost, J., Eisenbraun, E. J., Vick, K., Drew, W. A., and Young, J. 1966. Volatile compounds in ants: Identification of 4-methyl-3-heptanone from Pogonomyrmex ants. J. Insect Physiol. 12:1435-1441.

McLaughlin, J. R. 1996. Population monitoring of Lygus hesperus with female baited traps. Proceedings Beltwide Cotton Production Research Conferences. pp. 733-734.

Pureswaran, D. S. and Borden, J. H. 2003. Is bigger better? Size and pheromone production in the mountain pine beetle, Dendroctonus ponderosae Hopkins (Coleoptera: Scolytidae). J. Insect Behav. 16:765-782.

Rodriguez-Saona, C., Crafts-Bradner, S. J., Williams, L. III, and Paré, P. W. 2002. Lygus hesperus feeding and salivary gland extracts induce volatile emissions in plants. J. Chem. Ecol. 28:1733-1747.

SAPPINGTON, T. W. and TAYLOR, O. R. 1990. Developmental and environmental sources of pheromone variation in Colias eurytheme butterflies. J. Chem. Ecol. 16:2771-2786.

SCALES, A. L. 1968. Female tarnished plant bugs attract males. J. Econ. Entomol. 61:1466-1467.

ScotT, D. R. 1977. An annotated listing of host plants of Lygus hesperus Knight. Bull. Entomol. Soc. Am. 23:19-22.

SOKAL, R. R. and Rohlf, F. J. 1995. Biometry. 3rd edition, W.H. Freeman and Company, New York.

Strong, F. E., Sheldahl, J. A., Hughes, P. R., and Hussein, E. M. K. 1970. Reproductive biology of Lygus hesperus Knight. Hilgardia 40:105-147.

Wardle, A. R., Borden, J. H., Pierce, H. D. JR., and Gries, R. 2003. Volatile compounds released by disturbed and calm adults of the tarnished plant bug, Lygus lineolaris. J. Chem. Ecol. 29:931-944. 